(C) 2022, The Authors. Published by Elsevier Inc. and Fass Inc. on behalf of the American Dairy Science Association ${ }^{\circledR}$. This is an open access article under the CC BY license (http://creativecommons.org/licenses/by/4.0/).

\title{
Genetic parameters and association of national evaluations with breeding values for health traits in US organic Holstein cows
}

\author{
L. C. Hardie, ${ }^{1 *} \odot$ I. W. Haagen, ${ }^{1} \odot$ B. J. Heins, ${ }^{2} \odot$ and C. D. Dechow ${ }^{1} \odot$ \\ ${ }^{1}$ Department of Animal Science, Pennsylvania State University, University Park 16802 \\ ${ }^{2}$ Department of Animal Science, University of Minnesota, St. Paul 55108
}

\section{ABSTRACT}

Among other regulations, organic cows in the United States cannot receive antibiotics and preserve their organic status, emphasizing the importance of prevention of illness and benefit of high genetic merit for disease resistance. At the same time, data underlying national genetic evaluations primarily come from conventional cows, drawing concern to the possibility of a genotype by environment interaction whereby the value of a genotype varies depending on the environment, and potentially limits the relevance of these evaluations to organic cows. The objectives of this study were to characterize the genetics of and determine the presence of genotype by environment interaction for health traits in US organic dairy cows. Individual cow health data were obtained from 16 US Department of Agriculture certified organic dairy farms from across the United States that used artificial insemination and maintained detailed records. Data were obtained for the following traits: died, lameness, mastitis, metabolic diseases (displaced abomasum, ketosis, and milk fever), reproductive diseases (abortion, metritis, and retained placenta), transition health events (any health event occurring $21 \mathrm{~d}$ before or after parturition), and all health events. Binary phenotypes $(1=$ diseased, 0 $=$ otherwise) for 38,949 lactations on 19,139 Holstein cows were used. Genotypes from 2,347 cows with $87.5 \%$ or greater Holstein breed-based representation were incorporated into single-step multitrait threshold animal models that included stayability $(1=$ completed lactation, 0 = otherwise). Gibbs sampling was used. Genomic predicted transmitting abilities (gPTA) from national genetic evaluations were obtained for sires for production, fitness, health, and conformation traits. We approximated genetic correlations for sires using these gPTA and our estimated breeding values. We also

Received April 9, 2021.

Accepted August 24, 2021.

*Corresponding author: lhardie@psu.edu regressed health phenotypes on cow estimated breeding values and sire gPTA. Heritabilities ( \pm standard error) ranged from $0.03 \pm 0.01$ (reproductive diseases) to 0.11 \pm 0.03 (metabolic diseases). Most genetic correlations among health traits were positive, though the genetic correlation between metabolic disease and mastitis was $-0.42 \pm 0.17$. Approximate genetic correlations between disease resistance for our health trait categories and disease resistance for the nationally-evaluated health traits generally carried the expected sign with the strongest correlation for mastitis $(0.72 \pm 0.084)$. Regression coefficients carried the expected sign and were mostly different from zero, indicating that evaluations from primarily conventional herd data predicted health on organic farms. In conclusion, use of national evaluations for health traits should afford genetic improvement for health in US organic herds.

Key words: organic, health, genetics

\section{INTRODUCTION}

In the United States, genetic selection for improved disease resistance has been practiced indirectly on a national scale through emphasis on productive life and SCS since 1994 (VanRaden and Klaaskate, 1993; Shook and Schutz, 1994; Wiggans et al., 1994) and for udder conformation traits before that time (Thomas et al., 1984). More recently, direct selection for improved health has become available through large-scale genomic evaluations (Parker Gaddis et al., 2014, 2020; Vukasinovic et al., 2017), although genetic parameter estimates for health traits in US Holstein cows existed prior (Zwald et al., 2004a).

Maintaining healthy cows is critical to achieving high levels of animal welfare (von Keyserlingk et al., 2009; von Keyserlingk and Weary, 2017) and perhaps is even more critical on organic dairy farms to meet consumer expectation that organic farms provide better animal welfare (Hughner et al., 2007; Harwood and Drake, 2018). Cow health is also critical for organic dairy producers because US Department of Agriculture (USDA) organic regulations restrict the use of 
pharmaceuticals commonly used on conventional dairy farms, although there are a growing number of alternative remedies such as organic tinctures and essential oils to assist with healing (Sutherland et al., 2013; USDA-AMS, 2020; Brock et al., 2021). The prohibition of antibiotics and other USDA organic regulations such as the necessity for cows to graze, the prohibition of synthetic hormones, and the necessity of providing outdoor access, open the possibility of a genotype by environment interaction $(\mathbf{G} \times \mathbf{E})$ and a subsequent effect on response to selection when contrasting organic to conventional production.

Genotype by environment interaction is characterized by individuals with the same genotype performing differently based on environment and manifests in primarily 2 ways. First, there can be a scaling effect, in which case the magnitude of the response to selection differs between environments. In the second instance, there can be a reranking of animals across the 2 environments, where sires of one genotype are superior in one environment, but inferior in the second environment. Multiple methods are commonly used to determine the presence of $\mathrm{G} \times \mathrm{E}$ including comparing heritabilities and variance components across environments, identifying genetic correlations across environments that differ from unity, and regressing phenotypes from one environment on PTA or EBV established in the second environment (Weigel et al., 1999; Mathur, 2002; Kearney et al., 2004; Shabalina et al., 2021).

Organic cows comprise approximately $3 \%$ of the US dairy cow population (USDA-NASS, 2017). Coupled with the lower propensity for organic farmers to participate in Dairy Herd Improvement testing (Richert et al., 2013b), phenotypes underlying US national genetic evaluations primarily come from conventional cows. Therefore, it becomes feasible to determine $\mathrm{G} \times \mathrm{E}$ associated with organic dairy production by using genetic merits estimated from national genetic evaluations and phenotypes from organic herds.

The objective of this study was to perform a genetic evaluation and characterize $\mathrm{G} \times \mathrm{E}$ for health traits in US organic Holstein dairy cows. To that end, we estimated heritabilities for and genetic correlations among health traits in organic cows. Furthermore, using genetic merits estimated through national genetic evaluations, we approximated genetic correlations for corresponding traits and compared the odds of disease between organic and conventional environments.

\section{MATERIALS AND METHODS}

This research was approved by Penn State Institutional Animal Care and Use Committee (protocol \#47560).
Sixteen USDA certified organic farms identified by industry personnel as having thorough individual cow records and at least some breedings using AI, rather than complete reliance on herd bulls, were enrolled in the study. Farms were located throughout the continental United States and categorized as follows: east $(\mathrm{n}=$ $4)$, midwest $(\mathrm{n}=6)$, and west $(\mathrm{n}=6)$. All farms were visited by research personnel at least once between the years 2017 and 2019 to obtain individual cow identification, production, health, and reproduction data. Herd USDA organic certification ranged from before 2000 to 2016, and data from years before the herd becoming organic were eliminated.

\section{Phenotypes}

Health Traits. We retrieved health records through herd data backups from on-farm software (PCDART, Dairy Comp 305 or DHI-Plus) or through paper records provided by producers. Even though farms were selected based on recommendations as maintaining detailed herd records, farms varied in the number of diseases recorded or monitored. We asked producers to record, at a minimum, the following diseases: displaced abomasum (DA), ketosis, lameness (LAME), mastitis, metritis, milk fever, respiratory disease, retained placenta, and scours. Some producers provided records of more diseases.

Because of low incidence of some diseases, we categorized some diseases when establishing health traits (Table 1). We considered the following health traits: metabolic diseases (METB), including DA, milk fever, ketosis, and fatty liver; mastitis, consisting only of recorded cases of clinical mastitis; LAME, including any foot disease; any reproductive diseases (REPRO), including abortion, metritis, prolapse, and retained placenta; died with death listed as a health event or culling reason; any event during the transition (TRAN) period defined as $21 \mathrm{~d}$ before or after parturition (Drackley, 1999), and all events including those such as "pink eye" not meeting criteria for inclusion into a previous mentioned category or general statements of disease such as "sick." For TRAN, health events occurring 21 d before parturition were associated with the calving date of the subsequent lactation. Previous reports of significant positive genetic correlations between DA and ketosis (0.65) and retained placenta and metritis (0.56) suggest commonality to the genetic basis of these pairs of diseases, fostering their grouping as METB and REPRO, respectively (Parker Gaddis et al., 2014).

Eligible lactations for health traits began with the year of the first incidence of each disease for each herd. We assumed that any health trait with at least 1 event 
Table 1. Descriptive statistics of health traits

\begin{tabular}{lcccl}
\hline Health trait & $\begin{array}{c}\text { Number } \\
\text { of cows }\end{array}$ & $\begin{array}{c}\text { Number } \\
\text { of records }\end{array}$ & $\begin{array}{c}\text { Incidence }^{1} \\
(\%)\end{array}$ & Included subtraits \\
\hline All events & 19,139 & 38,949 & 32.6 & Any health event, culling reason excluded \\
Died & 18,675 & 37,670 & 5.6 & $\begin{array}{l}\text { Died (as event and culling reason) } \\
\text { Lameness }\end{array}$ \\
17,602 & 35,653 & 8.6 & $\begin{array}{l}\text { Lame (as event and culling reason), foot rot, digital dermatitis, laminitis, } \\
\text { warts) }\end{array}$ \\
Mastitis & 17,609 & 35,667 & 13.8 & Mastitis \\
Metabolic & 17,608 & 35,826 & 1.3 & Ketosis, fatty liver, milk fever, displaced abomasum \\
Reproductive & 18,834 & 38,178 & 7.4 & $\begin{array}{l}\text { Abortion, retained placenta, metritis, prolapse } \\
\text { Transition }\end{array}$ \\
& 18,773 & 37,960 & 12.1 & $\begin{array}{l}\text { Any health event occurring 21 d from parturition (culling reason of died and } \\
\text { abortion included) }\end{array}$ \\
\hline
\end{tabular}

${ }^{1}$ Incidence calculated as the percent of eligible lactations incurring at least 1 case of the health trait.

recorded on a given farm continued with recording until the most recent herd data backup was retrieved, noting that herds experienced variation in incidence across years. However, no herd-years of calving that contained at least 3 records experienced greater than $50 \%$ incidence of disease. Fifty percent has previously been used as incidence threshold for producer-recorded health data to minimize consideration of preventative treatments as cases of disease (Zwald et al., 2004a). Lactations greater than 5 were removed. For each eligible lactation, a score of 1 was assigned if a given health event occurred, and a score 0 was assigned otherwise. The number of records used for these health traits are provided in Table 1 and ranged from 35,653 (LAME) to 38,949 (all events) on 17,602 (LAME) to 19,139 (all events) cows.

Stayability. We also recorded stayability (STAY) for each cow lactation, defined as the binary outcome of the cow completing a lactation $(\mathrm{STAY}=1)$ or being culled or dying $(\mathrm{STAY}=0)$. A lactation was considered completed if a subsequent calving date was available for cows. As a lifelong measured trait, STAY potentially mitigates selection bias that could occur due to culling for traits correlated with the trait of interest (Hardie et al., 2021).

\section{Animal Relationships}

Pedigree. The pedigree used in these analyses was the same as in Hardie et al. (2021). For a phenotyped cow to be retained in the pedigree, she needed to have a Holstein sire and the first 3 generations of male lineage of her dam be Holstein or unknown breed. The pedigree for male ancestors was obtained from publicly available files from the Council on Dairy Cattle Breeding (CDCB; Bowie, MD). Unknown parent groups were created as the interaction of herd and birth year when ancestry was not known. In total, the pedigree contained 38,434 animals.
Genotypes. We retained genotypes of 2,347 cows. Cows were genotyped using the following commercially available SNP panels (count): GeneSeek Genomic Profiler-Super LD (36), GeneSeek Genomic Profiler LD Version 3 (45), Zoetis Low Density Version 2 (127), GGP Bovine 150K (506), GeneSeek Genomic Profiler LD Version 4 (34), Zoetis Low Density Version 4 (121), GGP Bovine 50K (472), Zoetis Low Density Version 5 (931), and other panels with less than 20 genotypes each (75). Genotypes were imputed to $80 \mathrm{k}$ at CDCB (Wiggans et al., 2019) and retained for animals with breed-based representation greater than or equal to 87.5\% Holstein. Quality control was performed on the genotypes using the software PREGSF90 in the BLUPF90 family of programs (Aguilar et al., 2011; Misztal et al., 2018). We removed SNP with call rates less than 0.90, SNP with minor allele frequency less than 0.05 , genotypes with call rates less than 0.90 , and genotypes of progeny with Mendelian conflicts with parents. Pedigree and SNP information were blended using a single-step approach to form an $\mathbf{H}$ matrix using PREGSF90. We used the default weight (1) on each SNP and method for establishing the genomic relationship, which is method 1 in VanRaden (2008).

\section{Genetic Evaluations}

Bivariate analyses including STAY and each of the health traits were performed to estimate variance components for estimation of heritabilities for the 7 health traits, and trivariate analyses including STAY and 2 health traits were used to estimate (co)variances for estimation of genetic correlations between pairs of the 7 health traits. Because the traits are binary in outcome, threshold models were used whereby a variable, "liability to disease" is assumed to follow a normal distribution and at a particular liability (threshold) the outcome of the binary variable changes from failure to success. 
Variance components for the calculations of heritabilities were estimated using the THRGIBBS1F90 program (version 2.116; Misztal et al., 2018). The following bivariate threshold animal model, written in matrix notation, was used:

$$
\boldsymbol{\lambda}=\mathbf{X} \boldsymbol{\beta}+\mathbf{Z}_{\mathbf{b}} \mathbf{b}+\mathbf{Z}_{\mathbf{c}} \mathbf{c}+\mathbf{Z}_{\mathbf{a}} \mathbf{a}+\mathbf{Z}_{\mathbf{p}} \mathbf{p}+\mathbf{e},
$$

where $\boldsymbol{\lambda}$ is a vector of the liability to a health incident or STAY; $\boldsymbol{\beta}$ is a vector of fixed effects including overall mean and the class effects of lactation and herd with incidence matrix $\mathbf{X} ; \mathbf{b}$ is a vector of the random effect of herd-year-season of birth (668 levels) fit for STAY and proportional to $N\left(0, \mathbf{I} \sigma_{b}^{2}\right)$, where $\mathbf{I}$ is the identity matrix and $\sigma_{b}^{2}$ is the variance of herd-year-season of birth; $\mathbf{c}$ is a vector of random herd-year-season of calving (771 levels) fit for the health trait and proportional to $N\left(0, \mathbf{I} \sigma_{c}^{2}\right)$, where $\sigma_{c}^{2}$ is the variance of herd-year-season of calving; $\mathbf{a}$ is the vector of the random effect of animal proportional to a multivariate normal distribution with mean0and covariancematrix $\left[\begin{array}{cc}\mathbf{H} \sigma_{a_{S T}}^{2} & \mathbf{H} \sigma_{a_{S T, H E A L T H}} \\ \mathbf{H} \sigma_{a_{S T, H E A L T H}} & \mathbf{H} \sigma_{a_{H E A L T H}}^{2}\end{array}\right]$, reflecting trait respective additive genetic variance $\sigma_{a}^{2}$, genetic covariance $\sigma_{a}$, and genetic relationship matrix $\mathbf{H} ; \mathbf{p}$ is the vector of random permanent environmental effects across lactations, fit for all traits and proportional to a multivariate normal distribution with mean 0 and covariance matrix $\left[\begin{array}{cc}\mathbf{I} \sigma_{p_{S T}}^{2} & \mathbf{I} \sigma_{p_{S T, H E A L T H}} \\ \mathbf{I} \sigma_{p_{S T, H E A L T H}} & \mathbf{I} \sigma_{p_{H E A L T H}}^{2}\end{array}\right]$, reflecting trait respective permanent environmental variance $\sigma_{p}^{2}$, and permanent environmental covariance $\sigma_{p}$; and $\mathbf{e}$ is the error with covariance matrix $\left[\begin{array}{cc}\mathbf{I} & \mathbf{I} \sigma_{e_{S T, H E A L T H}} \\ \mathbf{I} \sigma_{e_{S T, H E A L T H}} & \mathbf{I}\end{array}\right]$, reflecting error variances set to 1 and covariance $\sigma_{e}$. Matrices $\mathbf{Z}_{\mathrm{b}}, \mathbf{Z}_{\mathrm{c}}, \mathbf{Z}_{\mathrm{a}}$, and $\mathbf{Z}_{\mathbf{p}}$ contain the incidence for their respective random effects. Chains of at least 200,000 iterations with the first 50,000 discarded as burn-in were used, saving every 50th sample. Plots of individual samples for heritabilities and genetic correlations were inspected for convergence, and if deemed necessary, an additional 200,000 iterations were run. These parameters were also required to have a minimum of approximately 10 independent samples. We used the procedures outlined in Misztal et al. (2013) and implemented in the POSTGIBBSF90 software (version 3.14, Misztal et al., 2018) to estimate the reliabilities of genomic (g)EBV.
Using a model similar to that of the bivariate analyses, trivariate analyses were run to estimate genetic correlations among the health traits where the response variables were STAY and 2 health traits for each analysis. All trivariate analyses were run with a chain of at least 400,000 iterations and 50,000 burn-in.

\section{Approximate Genetic Correlations}

National genetic evaluations from the December 2020 official proof for sires were obtained from files freely available through CDCB. Retaining genomic predictions for bulls with reliability greater than 0.25 for health traits measured in our organic cows, we approximated genetic correlations between our health traits and nationally-evaluated traits of interest, including health, production, fitness, and conformation, adapting the method of Calo et al. (1973) as implemented with the following equation:

$$
\hat{r}_{g_{1,2}}=r_{1,2} \times \frac{\sqrt{\left(\sum_{i=1}^{n} R E L_{1 i}\right)\left(\sum_{i=1}^{n} R E L_{2 i}\right)}}{\sum_{i=1}^{n}\left(R E L_{1 i} \times R E L_{2 i}\right)},
$$

where $\hat{r}_{g_{1,2}}$ is the approximated genetic correlation between trait 1 and trait $2 ; r_{1,2}$ is the Pearson correlation between the estimated breeding values generated for our health traits and the genomic (g)PTA provided through national evaluations; $R E L_{1 i}$ is the reliability of the nationally-evaluated gPTA as provided by CDCB for bull $i$; and $R E L_{2 i}$ is the reliability of our health trait as calculated with the following equation:

$$
R E L_{2 i}=1-\frac{P E V_{2 i}}{\sigma_{a_{2}}^{2}},
$$

where $P E V_{2 i}$ is the prediction error variance for the estimated breeding value and $\sigma_{a_{2}}^{2}$ is the additive genetic variance. Standard errors for the approximate genetic correlations were calculated using the following method:

$$
\mathrm{SE}=\sqrt{\frac{1-\hat{r}_{g_{1,2}^{2}}^{2}}{n-2}}
$$

where SE is the standard error, $\hat{r}_{g_{1,2}}^{2}$ is the square of the approximated genetic correlation, and $n$ is the number of sires. Significance was declared based on a 2-tailed $t$-test with significance threshold equal to 0.05 . 


\section{Regression on Sire gPTA}

Cow health phenotypes were regressed on their respective sire gPTA from national genetic evaluations for DA, ketosis, mastitis, metritis, milk fever, and retained placenta. We also considered a binary trait (three quarter), reflecting the number of milking quarters of an udder where 3 or fewer quarters milking was assigned a phenotype of 1 (case) and milking out of all 4 quarters was assigned zero (control). These phenotypes were regressed on sire gPTA for mastitis. Because treatment with antibiotics necessitates that a cow loses her status as organic, organic farmers oftentimes choose to dry an infected quarter as an alternative solution to handle mastitis cases (Brock et al., 2021). These logistic regressions were performed separately by lactation, only for each of the first 3 lactations because of declining cow numbers in later parities, using the following model:

$$
\lambda_{i j k l}=\mu+\beta_{1} g P T A_{i j k l}+h_{j}+h y_{j k}+h s_{j l}+e_{i j k l},
$$

where $\lambda$ is the liability to disease on the underlying scale for the health trait, $\mu$ is the intercept, $g P T A$ is the fixed covariate of the gPTA of the sire for the health trait with coefficient $\beta_{1}, h$ is the random effect of herd $j, h y$ is the random effect of herd $j$ by year of calving $k, h s$ is the random effect of herd $j$ by season of calving $l$, and $e$ is the random residual with variance $\pi^{2} / 3$, following a logit link function. Because some herds were very small, with no more than 1 calving in some years or seasons, we decided to separate calving year and season and consider the herd effects as random to foster convergence. In a linear model, when the trait of the phenotype is the same as gPTA, the expectation for the coefficient on sire gPTA is 1 ; however, although the binary nature of the response variable complicates calculation of the magnitude of the coefficient, one can readily expect a positive coefficient.

The gPTA marking the 25th, 50th, and 75 th percentiles were determined, and odds ratio comparing the odds of disease for daughters of sires having gPTA at either the 25 th or 75 th percentile to the 50 th percentile were computed. The expected odds ratios were calculated by first calculating the expected odds using the mean lactational probability of disease reported for the national data underlying the evaluations (Parker Gaddis et al., 2012). For example, the frequency (p) of mastitis in first lactation cows reported by CDCB is 0.0953 (Parker Gaddis et al., 2012), and our median gPTA for mastitis was 0 ; thus, the corresponding odds of disease at the 50 th percentile $[\mathrm{p} /(1-\mathrm{p})]$ was 0.105 .
The 25th percentile gPTA for mastitis resistance in our data was $-1.1 \%$. The expected frequency of mastitis for cows in the 25th percentile is the sum of 0.0953 and 0.011, equaling 0.106, corresponding to an odds of 0.119 . The expected odds ratio for mastitis in the 25 th versus 50 th percentile is $0.119 / 0.105$, or $1.13: 1$.

\section{Regression on Own Genomic Prediction}

Cow health trait gPTA estimated by the CDCB in the national August 2020 official evaluation were obtained from Neogen and Zoetis. Mastitis and lameness standardized transmitting abilities (STA) estimated by Zoetis at that same time were obtained for cows genotyped at Zoetis. These traits are adjusted to a mean of 100 and standard deviation of 5, with STA greater than 100 reflecting greater disease resistance (McNeel et al., 2017). Health trait gPTA estimated by CDCB are centered at 0 , and thus were simply multiplied by 2 to convert to gEBV. For all traits, logistic regressions were performed using a model similar to the regressions on sire gPTA but with gEBV or STA in place of gPTA. Also, the fixed effect of lactation was added as a covariate, and the random effect of cow was added as a class variable because all available lactations for a cow, up through lactation 5 , were used. Specifically, phenotypes for mastitis and died were regressed on gEBV for mastitis and livability, respectively. Due to the small number of genotyped cows, METB was regressed on the sum of the gEBV for ketosis, DA, and milk fever and REPRO on the sum of gEBV for metritis and retained placenta rather than performing individual trait regressions. Mastitis and LAME phenotypes were regressed on their corresponding individual trait STA for cows genotyped at Zoetis. We did not sum Zoetis estimates for metabolic or reproductive traits as was done for CDCB gEBV because they were expressed as STA. The STA for individual diseases have different underlying distributions; therefore, a +1 standard deviation for DA is associated with a different expectation for the percentage of diseased daughters than a +1 standard deviation for ketosis. Odds ratios were calculated in a manner similar to that used for sire regressions above but with cow gEBV or STA at the 25th, 50th, and 75th percentile.

For a continuous trait regressed on sire gPTA or own $\mathrm{gEBV}$, the expected regression coefficient is 1 . However, the binary nature of our disease response variables complicated calculations because the expected coefficients were dependent on disease frequency in the population used to generate PTA, which was generally not known, and the manner of PTA expression, which was usually 
not on the underlying scale. Nevertheless, we expected a positive coefficient and lower odds of a disease for sires with high genetic merit for disease resistance.

\section{RESULTS AND DISCUSSION}

Our aim was to establish genetic parameters and characterize $\mathrm{G} \times \mathrm{E}$ for health traits for cows in organic herds. Depending on the trait, up to 38,949 lactations on 19,139 Holstein cows were used. Even though we did not use a random sample of herds, we believe that our results can still provide valuable insight into the improvement of the genetics of health among organic Holstein cows because we included cows from across the United States, a variety of herd sizes, and a range of levels of pasture inclusion in the diet. Perhaps the greatest concern was that our restriction of herds to those that used at least some AI, which is more common among conventional farms (Richert et al., 2013b), may ultimately have suppressed our ability to capture $\mathrm{G} \times \mathrm{E}$. Furthermore, by recruiting herds that were recommended as maintaining detailed records, our reported incidence of disease cannot be assumed as representative of the US organic dairy industry (Table 1). Keeping detailed records could imply a conscientiousness among our producers that would lead to greater prevention of disease, and thus lower disease incidence. On the other hand, we encouraged farmers to be thorough when reporting diseases (e.g. asking for records of disease, even if it was not treated), which could raise the disease incidence from what is generally reported. Nevertheless, recording disease was at the farmer's discretion; therefore, we expected variability in severity, thoroughness of detection, or other aspects of a case of a disease necessary to prompt recording.

Our incidences of disease were generally comparable to what has been reported nationally for the US dairy industry, which was primarily based on conventional cows (Zwald et al., 2004a; Parker Gaddis et al., 2012; Vukasinovic et al., 2017). Our mastitis incidence $(13.8 \%)$ was similar to that of Parker Gaddis et al. (2012; 12.3\%) though less than Zwald et al. (2004a; $20 \%)$ and Vukasinovic et al. (2017; 25\%). Our incidence for on-farm death $(5.3 \%)$ was somewhat lower than the national estimate (6\%; VanRaden et al., 2016). We combined incidences of METB (1.3\%; ketosis, DA, and milk fever) and REPRO (7.6\%; metritis and retained placenta) because of the low occurrence of any one trait. Despite these combinations, our incidences remained lower than reported for any of these individual metabolic traits $(2-10 \%)$ and toward the low end for these reproductive traits (4.6-21\%; Zwald et al., 2004a; Parker Gaddis et al., 2012; Vukasinovic et al., 2017).
Multiple reasons could explain the low incidence, including the sensitivity of disease definition (Richert et al., 2013a). Also, the data used in the 3 largest US health trait genetic studies were restricted to greater minimum incidence rates than what we used, including the following: trait-dependent minimum lactational incidence rates up to 0.05 for mastitis (Zwald et al., 2004a), at least 1 incident per herd-year (Parker Gaddis et al., 2012), and at least 1 incident per herd-year-season of calving, except for a few small herd-year-seasons (Vukasinovic et al., 2017). On the other hand, we only required 1 incident of a health trait to include lactations from the year of occurrence and all subsequent years. We believed that instituting minimum lactational incidences might be too restrictive because we used data from small herds, and some of our participating producers and previous reports indicated a drop in disease upon transitioning to organic production (Brock et al., 2021). Previous research has suggested lower incidence of disease in both US and European organic farms when compared with conventional farms (Hardeng and Edge, 2001; Byström et al., 2002; Richert et al., 2013a). Even though regulations for organic farms differ among countries such as the permittance of antibiotics as a treatment on European organic farms, they are very similar in many ways such as emphasizing forage in the diet, prohibiting synthetic hormones, and requiring accessibility to the outdoors (European Union, 2020; USDA-AMS, 2020). Hardeng and Edge (2001) and Hamilton et al. (2006) reported lower odds for mastitis on organic farms than on conventional farms, supported by the association of regular access to pasture with a reduction in risk of mastitis (Firth et al., 2019). Hardeng and Edge (2001) also reported lower odds for metabolic disorders on organic farms. In a multiregional study, Richert et al. (2013a) found that higher farmer-identified incidence of mastitis but not ketosis was associated with conventional farming. Byström et al. (2002) reported that when compared with a partner conventional research herd, a tendency toward fewer cows requiring treatment and fewer veterinary treatments per cow was observed in the organic herd during the first 10 weeks postcalving, although mastitis incidence was slightly higher in the organic herd. The authors report a corresponding lower milk yield and lower liveweight change during this time, fitting the finding from other researchers that lower milk yield is associated with reduced ketosis incidence (Hardeng and Edge, 2001; Richert et al., 2013a). Greater percent of forage in the organic cow diet was reported as the primary difference between the organic and conventional farms studied in 
Byström et al. (2002) and Hamilton et al. (2006) and may be a factor in differences in incidence.

\section{Genetic Parameters for Health Traits}

Heritability estimates are listed on the diagonal in Table 2. Estimates were low, ranging from 0.03 (REPRO, TRAN) to 0.11 (METB). These estimates were similar (mastitis) to slightly lower (METB, REPRO) than those previously reported for the US Holstein population (Zwald et al., 2004a; Parker Gaddis et al., 2014; Vukasinovic et al., 2017). Heritability estimates for DA are generally the greatest among health traits ranging from 0.08 to 0.32 and followed by ketosis (Zwald et al., 2004a; Parker Gaddis et al., 2014; Vukasinovic et al., 2017). Although our heritability estimate for METB was our highest, it was in the low end of the reported range, possibly because our low incidence suppressed genetic variation. For likely the same reason, our heritability estimate for REPRO was lower than previous estimates for metritis and retained placenta, ranging from 0.03 to 0.36 (Zwald et al., 2004a; Parker Gaddis et al., 2014; Vukasinovic et al., 2017). Our estimate for TRAN (0.03) and all events (0.05) was lower than previously estimated for any disease within $50 \mathrm{~d}$ postpartum in primiparous and mature cows $(0.10$; Zwald et al., 2004a).

Genetic correlations among the health traits and with STAY are also listed in Table 2 and ranged from $-0.42 \pm 0.17$ between METB and mastitis to $-0.94 \pm$ 0.07 between died and STAY. Previous genetic correlations between mastitis and DA $(0.02 \pm 0.16$ to $0.08 \pm$ $0.17)$ as well as between mastitis and ketosis $(-0.20 \pm$ 0.24 to $0.17 \pm 0.21$ ) did not differ from zero (Zwald et al., 2004b; Parker Gaddis et al., 2014). Perhaps the negative genetic correlation we estimated could be explained by the differences in the nature of these diseases. Metabolic disorders reflect the metabolism of feedstuffs, whereas mastitis reflects an infection. Furthermore, metabolic diseases generally occur in early lactation, whereas mastitis cases are more likely to occur throughout lactation (Zwald et al., 2004a). However, a positive phenotypic relationship between metabolic disease and mastitis has been shown (Goff, 2012).

Other strong genetic correlations included $0.93 \pm$ 0.03 between the occurrence of a health event during the transition period and any health event during a lactation, and $0.90 \pm 0.05$ between mastitis and the occurrence of any health event during a lactation. These genetic correlations were unsurprising in light of transition-period health events and mastitis being a subset of any health event.

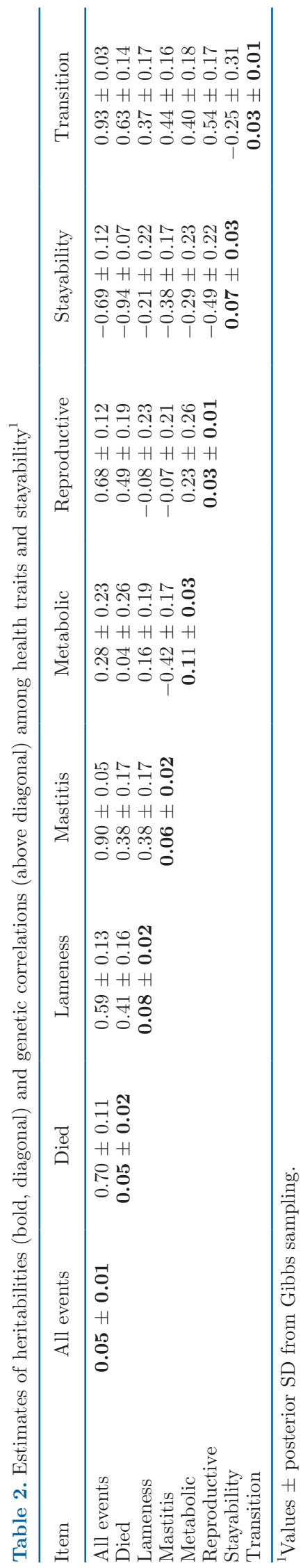




\section{Approximate Genetic Correlations Between Our Health and Nationally Evaluated Traits}

Health Traits. In general, approximate genetic correlations were strong between our gPTA and those obtained from CDCB for their respective health traits (Table 3). The CDCB reports their gPTA in terms of disease resistance (higher equals healthier), and thus we reversed the sign of our disease liability estimates to also represent resistance. Therefore, positive approximate genetic correlations between health traits reflected improved disease resistance in both the organic and conventional environments. Approximate genetic correlations $( \pm \mathrm{SE})$ were $0.72 \pm 0.084,0.42 \pm 0.109$, and $0.33 \pm 0.105$ with METB for mastitis, DA, and ketosis, respectively, and $0.51 \pm 0.111$ and $0.44 \pm 0.109$ with REPRO for metritis and retained placenta, respectively. When the same trait is evaluated in different environments, genetic correlations less than 0.8 suggest a $\mathrm{G} \times \mathrm{E}$ interaction (Robertson, 1959); therefore, our data suggest a $G \times E$ interaction for mastitis. Genetic correlations reported by Shabalina et al. (2021) also suggested a $G \times E$ interaction for mastitis, ranging from 0.41 to 0.44 depending on method used to establish animal relationships. These data suggest the need for further research into potential reranking among individuals. In line with our strong negative genetic correlation between mastitis and METB, the approximate genetic correlation between METB and national evaluations for mastitis resistance was $-0.44 \pm 0.068$, suggesting that higher mastitis resistance was associated with higher genetic predisposition for metabolic disorders in these herds.

Production and Fitness Traits. The genetic relationship between Grazing Merit (Gay et al., 2014) and health traits tended to be more strongly favorable than the genetic relationship between Net Merit (VanRaden, 2004; VanRaden et al., 2018) and our health traits. The Grazing Merit index was developed to improve the profitability of cows in herds using grazing; therefore, organic farmers, who are required to use grazing, are an intended audience for this index. Productive life and livability were both strongly correlated with the majority of our health traits, with greater susceptibility to disease associated with shorter lives or increased risk of death. With livability (resistance to dying on-farm) and our trait of died, both a measure of on-farm death, we expected a stronger correlation than $0.62(0.099)$. Milk yield was not associated with any health trait, but greater fat yield and percent was associated with greater susceptibility to disease for most health traits. Lack of genetic association between milk yield and metabolic diseases is consistent with previously approximated genetic correlations in US Holstein dairy cows (Parker Gaddis et al., 2014; Vukasinovic et al., 2017). In agreement with our findings, these studies approximated genetic correlations for metabolic diseases of approximately zero. However, they reported unfavorable relationships between mastitis and milk yield, which our data do numerically suggest, and inconsistent associations between reproductive diseases and milk yield.

Favorable relationships were generally observed between fitness and health traits. We estimated a strong correlation $(-0.61)$ between mastitis and SCS, indicating that greater genetic resistance to mastitis is associated with genetic predisposition to produce fewer somatic cells in the milk, as intended by the long time use of SCS as an indicator for mastitis resistance (Shook and Schutz, 1994). For all health traits, there was a strong and favorable relationship with the fertility traits daughter pregnancy rate and cow conception rate, which closely followed previously approximated genetic correlations between health and fertility traits in US dairy cows (Parker Gaddis et al., 2014; Vukasinovic et al., 2017). Cows with higher gPTA for fertility were genetically less susceptible to disease. Cows less likely to encounter difficult calvings were generally also less susceptible to disease as indicated by the negative genetic correlation between daughter calving ease and most health traits.

Conformation Traits. In general, conformation traits were not as strongly correlated with health traits as the other trait categories. However, there are few traits and trends that we consider noteworthy. Dairy form was either numerically or significantly $(P<0.05)$ negatively correlated with all health trait categories that we considered, indicating that cows that are more angular or open in their rib are more liable to disease. Udder depth was significantly correlated with mastitis susceptibility, with deeper udders associated with greater frequency of mastitis. This finding follows many studies that demonstrate udder depth as the type trait with the strongest relationship with SCC or mastitis (Rogers et al., 1991; Rupp and Boichard, 1999; Nash et al., 2000). However, there was no association between mastitis susceptibility and udder composite, which is contrary to previous reports of favorable genetic relationships between udder composite and mastitis resistance (Rogers et al., 1998; Gernand and Konig, 2014). The cause of unfavorable relationship between udder traits and metabolic disorders is unclear but coincides with the negative relationship established between mastitis and metabolic disorders by our genetic correlations and approximate genetic correlations.

There was a significant genetic relationship between foot angle and lameness, with steeper heels associated with greater susceptibility to lameness, but there was 
Hardie et al.: GENETICS OF HEALTH IN US ORGANIC HOLSTEINS

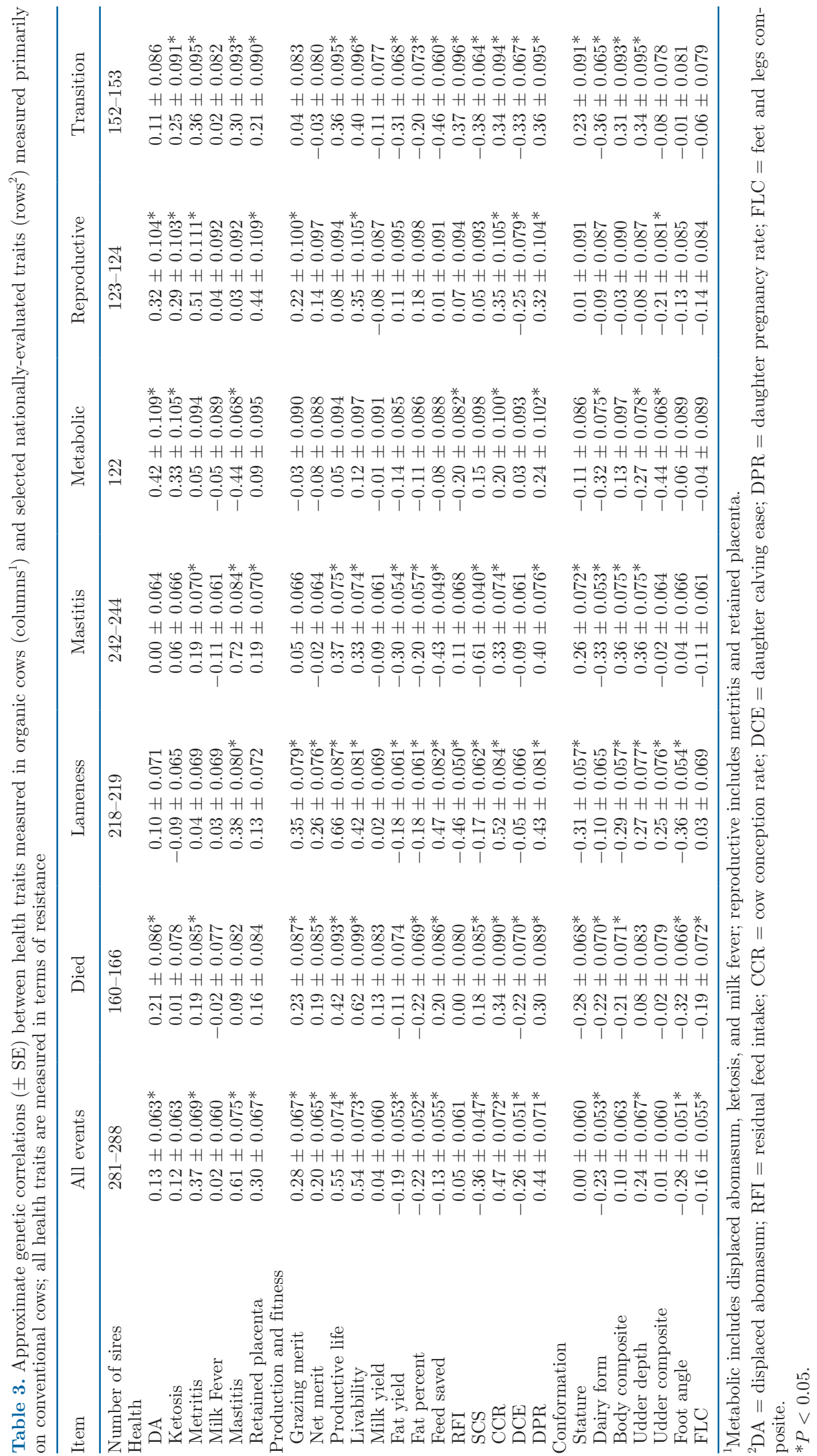


no overall relationship between feet and leg composite and lameness. A steeper heel is often genetically associated with improved locomotion (van der Waaij et al., 2005; Onyiro and Brotherstone, 2008; Ring et al., 2018), but generally only weakly associated with genetic predisposition for hoof diseases (van der Linde et al., 2010; Ødegård et al., 2014). Significant positive genetic correlations with increased incidence of white line disease (van der Waaij et al., 2005), digital dermatitis (van der Linde et al., 2010), and toe ulcers (Oliveira Junior et al., 2021) have been found. van der Linde et al. (2010) also reported a significant negative genetic correlation between interdigital dermatitis and foot angle. The absence of a genetic correlation between feet and legs composite and lameness coincided with a previously reported low negative genetic correlation between lameness susceptibility reported in producerrecorded data and feet and legs composite in Ireland (Ring et al., 2018).

\section{Regressions on Genetic Predictions}

We compared odds ratios for disease based on our regression coefficients with expected odds ratios because differences in disease frequency in our data and the data used to derive gPTA affect regression coefficients and make it unclear whether response to selection is greater or less than expected. When estimable, all coefficients numerically or significantly suggested a decrease in liability to disease with increase in sire gPTA for disease resistance (Table 4). The relationships between liability and gPTA for mastitis and DA were the strongest throughout all 3 lactations $(P<$ 0.01 ). Our odds ratios were most notably and consistently different from expected for DA with estimated ratios 0.2 to 0.3 higher for the ratio of 25 th to 50 th percentile, and approximately 0.1 lower for the 75th to 50 th percentile. Overall, our odds ratios showed the greatest deviation from expected odds ratios for third parity and suggested greater than expected response to selection could occur. Perhaps with restrictions on treatments such as antibiotics, the cow is better able to express her true genetic risk or resistance to disease.

Regression coefficients for the liability of disease on the cow's own gEBV or STA were significant in the expected direction except for lameness, which may indicate a lack of observations rather than a lack of true association (Table 5). All odds ratios for cows with genomic predictions at the 25 th percentile (less resistant) showed greater or no different odds to disease from the 50th percentile. The opposite held true for cows at the 75th percentile. Regardless of source of prediction, cows with genomic predictions at the 25 th percentile were at least $30 \%$ more likely to get mastitis compared with individuals with predictions at the median. These, along with metabolic diseases, were the highest odds ratios for all diseases. Expected odds ratios based on gEBV for mastitis were $1.15: 1$ and $0.85: 1$ for the 25 th and 75 th percentiles relative to the 50th percentile, respectively (data not shown).

Mastitis is the most commonly reported health issue among organic farmers (Brock et al., 2021), and our data support this finding. It has been suggested and demonstrated that organic farmers rely more heavily on drying off infected quarters as an alternative to traditional antibiotic treatments such as blanket dry cow therapy protocols (Garmo et al., 2010; Richert et al., 2013b). Therefore, we regressed incidence of 3 or fewer quarters on sire gPTA for mastitis. The relationship between gPTA and odds of becoming 3-quartered appeared to increase with lactation; a significant relationship between liability to becoming 3-quartered and sire gPTA was found for lactations 2 and 3. Future work more closely looking at the effects of mastitis in later parity organic cows may be warranted.

\section{CONCLUSIONS}

This study characterized the genetics of health traits in organic dairy cows and explored the presence of a $\mathrm{G} \times \mathrm{E}$ interaction between conventional and organic dairying. Although small, there is a heritable component to health traits, fostering their genetic improvement in the organic environment. Genetic correlations among health traits were generally moderate as seen in national genetic evaluations. Genotype by environment interactions appeared to be present to some degree, as evident by approximate genetic correlations between our and national gPTA estimates for health traits with values less than one and greater-than-expected response to selection, but may be suppressed due to the nonrandom selection of herds. However, as evident by positive approximate genetic correlations between health traits evaluated in conventional and organic environments, genetic improvement for health traits among organic dairy cows is achievable by using nationally available evaluations.

\section{ACKNOWLEDGMENTS}

Computations for this research were performed on the Pennsylvania State University's Institute for Computational and Data Sciences Advanced CyberInfrastructure (ICDS-ACI, University Park, PA). We are grateful for the contributions of our collaborating farms and appreciate financial support received through USDA 
Hardie et al.: GENETICS OF HEALTH IN US ORGANIC HOLSTEINS

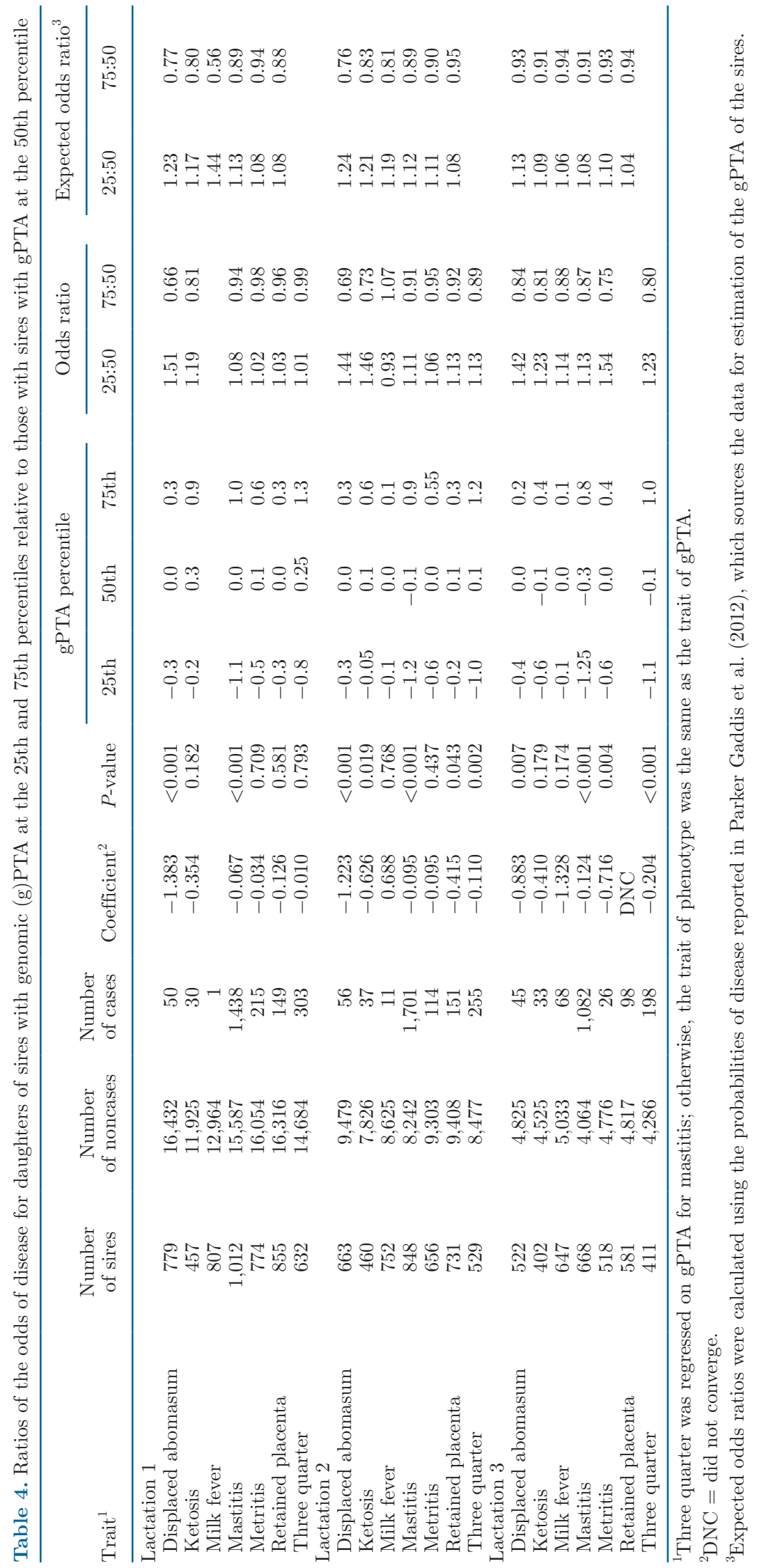


National Institute of Food and Agriculture (NIFA), Organic Agriculture Research and Extension Initiative (OREI), competitive grant no. 2016-51300-25862 (Washington, DC). The authors have not stated any conflicts of interest.

\section{REFERENCES}

Aguilar, I., I. Misztal, A. Legarra, and S. Tsuruta. 2011. Efficient computation of the genomic relationship matrix and other matrices used in single-step evaluation. J. Anim. Breed. Genet. 128:422428. https://doi.org/10.1111/j.1439-0388.2010.00912.x.

Brock, C. C., J. A. Pempek, D. Jackson-Smith, K. Weaver, L. da Costa, and G. G. Habing. 2021. Organic dairy producer experiences and decisions related to disease prevention and treatment. J. Dairy Sci. 104:5867-5880. https://doi.org/10.3168/jds.2020-19621.

Byström, S., S. Jonsson, and K. Martinsson. 2002. Organic versus conventional dairy farming-studies from the Öjebyn Project. Pages 179-184 in Proceedings of the UK Organic Research 2002 Conference. Organic Centre Wales.

Calo, L. L., R. E. McDowell, L. D. VanVleck, and P. D. Miller. 1973. Genetic aspects of beef production among Holstein-Friesians pedigree selected for milk production. J. Anim. Sci. 37:676-682. https: //doi.org/10.2527/jas1973.373676x.

Drackley, J. K. 1999. Biology of dairy cows during the transition period: The final frontier? J. Dairy Sci. 82:2259-2273. https://doi .org/10.3168/jds.S0022-0302(99)75474-3.

European Union. 2020. Consolidated Text: Commission Regulation (EC) No 889/2008 of 5 September 2008 Laying down Detailed Rules for the Implementation of Council Regulation (EC) No 834/2007 on Organic Production and Labelling of Organic Products with Regard to Organic Production. Accessed May 1, 2020. https://eur-lex.europa.eu/legal-content/EN/TXT/?qid= 1588153420644\&uri=CELEX:02008R0889-20200107.

Firth, C. L., C. Laubichler, C. Schleicher, K. Fuchs, A. Käsbohrer, C. Egger-Danner, J. Köfer, and W. Obritzhauser. 2019. Relationship between the probability of veterinary-diagnosed bovine mastitis occurring and farm management risk factors on small dairy farms in Austria. J. Dairy Sci. 102:4452-4463. https://doi.org/10.3168/ jds.2018-15657.

Garmo, R. T., S. Waage, S. Sviland, B. I. Henriksen, O. Østerås, and O. Reksen. 2010. Reproductive performance, udder health, and antibiotic resistance in mastitis bacteria isolated from Norwegian Red cows in conventional and organic farming. Acta Vet. Scand. 52:11. https://doi.org/10.1186/1751-0147-52-11.

Gay, K. D., N. Widmar, T. Nennich, A. Schinckel, J. Cole, and M. Schutz. 2014. Development of a lifetime merit-based selection index for US dairy grazing systems. J. Dairy Sci. 97:4568-4578. https://doi.org/10.3168/jds.2013-7474.

Gernand, E., and S. Konig. 2014. Random regression test-day mode for clinical mastitis: Genetic parameters, model comparison, and correlations with indicator traits. J. Dairy Sci. 97:3953-3963. https://doi.org/10.3168/jds.2013-7830.

Goff, J. P. 2012. Periparturient immune suppression: Causes and effects in the cow. Accessed Feb. 1, 2021. https://www.vetfolio .com/learn/article/periparturient-immune-suppression-causes-and -effects-in-the-cow.

Hamilton, C., U. Emanuelson, K. Forslund, I. Hansson, and T. Ekman. 2006. Mastitis and related management factors in certified organic dairy herds in Sweden. Acta Vet. Scand. 48:11. https://doi .org/10.1186/1751-0147-48-11.

Hardeng, F., and V. L. Edge. 2001. Mastitis, ketosis, and milk fever in 31 organic and 93 conventional Norwegian dairy herds. J. Dairy Sci. 84:2673-2679. https://doi.org/10.3168/jds.S0022 -0302(01)74721-2.

Hardie, L. C., B. J. Heins, and C. D. Dechow. 2021. Genetic parameters for stayability of Holsteins in US organic herds. J. Dairy Sci. 104:4507-4515. https://doi.org/10.3168/jds.2020-19399. 
Harwood, W. S., and M. A. Drake. 2018. Identification and characterization of fluid milk consumer groups. J. Dairy Sci. 101:8860-8874. https://doi.org/10.3168/jds.2018-14855.

Hughner, R. S., P. McDonagh, A. Prothero, C. J. Shultz, and J. Stanton. 2007. Who are organic food consumers? A compilation and review of why people purchase organic food. J. Consum. Behav. 6:94-110. https://doi.org/10.1002/cb.210.

Kearney, J. F., M. M. Schutz, and P. J. Boettcher. 2004. Genotype $\times$ environment interaction for grazing vs. confinement. II. Health and reproduction traits. J. Dairy Sci. 87:510-516. https://doi.org/ 10.3168/jds.S0022-0302(04)73190-2.

Mathur, P. K. 2002. Methods for estimation and use of genotypeenvironment interactions. Pages 2001-2002 in 7th World Congress on Genetics Applied to Livestock Production. World Congress on Genetics Applied to Livestock Production Digital Archive.

McNeel, A. K., B. C. Reiter, D. Weigel, J. Osterstock, and F. A. Di Croce. 2017. Validation of genomic predictions for wellness traits in US Holstein cows. J. Dairy Sci. 100:9115-9124. https://doi.org/ 10.3168/jds.2016-12323.

Misztal, I., S. Tsuruta, I. Aguilar, A. Legarra, P. M. VanRaden, and T. J. Lawlor. 2013. Methods to approximate reliabilities in single-step genomic evaluation. J. Dairy Sci. 96:647-654. https://doi.org/10 $.3168 /$ jds.2012-5656.

Misztal, I., S. Tsuruta, D. Lourenco, I. Aguilar, A. Legarra, and Z. Vitezica. 2018. Manual for BLUPF90 Family of Programs. Accessed Feb. 9, 2020. http://nce.ads.uga.edu/wiki/doku.php?id= documentation.

Nash, D. L., G. W. Rogers, J. B. Cooper, G. L. Hargrove, J. F. Keown, and L. B. Hansen. 2000. Heritability of clinical mastitis incidence and relationships with sire transmitting abilities for somatic cell score, udder type traits, productive life, and protein yield. J. Dairy Sci. 83:2350-2360. https://doi.org/10.3168/jds.S0022 $-0302(00) 75123-\mathrm{X}$.

Ødegård, C., M. Svendsen, and B. Heringstad. 2014. Genetic correlations between claw health and feet and leg conformation in Norwegian Red cows. J. Dairy Sci. 97:4522-4529. https://doi.org/10 $.3168 /$ jds.2013-7837.

Oliveira, G. A. Junior., F. Schenkel, L. Alcantara, K. Houlahan, C. Lynch, and C. Baes. 2021. Estimated genetic parameters for all genetically evaluated traits in Canadian Holsteins. J. Dairy Sci. 104:9002-9015. https://doi.org/10.3168/jds.2021-20227.

Onyiro, O. M., and S. Brotherstone. 2008. Genetic analysis of locomotion and associated conformation traits of Holstein-Friesian dairy cows managed in different housing systems. J. Dairy Sci. 91:322328. https://doi.org/10.3168/jds.2007-0514.

Parker Gaddis, K. L., J. Cole, J. Clay, and C. Maltecca. 2014. Genomic selection for producer-recorded health event data in US dairy cattle. J. Dairy Sci. 97:3190-3199. https://doi.org/10.3168/ jds.2013-7543.

Parker Gaddis, K. L., P. VanRaden, J. Cole, H. Norman, E. Nicolazzi, and J. Durr. 2020. Symposium review: Development, implementation, and perspectives of health evaluations in the United States. J. Dairy Sci. 103:5354-5365. https://doi.org/10.3168/jds.2019-17687.

Parker Gaddis, K. L., J. B. Cole, J. S. Clay, and C. Maltecca. 2012. Incidence validation and relationship analysis of producer-recorded health event data from on-farm computer systems in the United States. J. Dairy Sci. 95:5422-5435. https://doi.org/10.3168/jds .2012-5572.

Richert, R. M., K. Cicconi, M. Gamroth, Y. Schukken, K. Stiglbauer, and P. Ruegg. 2013a. Risk factors for clinical mastitis, ketosis, and pneumonia in dairy cattle on organic and small conventional farms in the United States. J. Dairy Sci. 96:4269-4285. https://doi.org/ 10.3168/jds.2012-5980.

Richert, R. M., K. Cicconi, M. Gamroth, Y. H. Schukken, K. E. Stiglbauer, and P. L. Ruegg. 2013b. Management factors associated with veterinary usage by organic and conventional dairy farms. J. Am. Vet. Med. Assoc. 242:1732-1743. https://doi.org/10.2460/ javma.242.12.1732.

Ring, S. C., A. J. Twomey, N. Byrne, M. Kelleher, T. Pabiou, M. Doherty, and D. Berry. 2018. Genetic selection for hoof health traits and cow mobility scores can accelerate the rate of genetic gain in producer-scored lameness in dairy cows. J. Dairy Sci. 101:10034-10047. https://doi.org/10.3168/jds.2018-15009.

Robertson, A. 1959. The sampling variance of the genetic correlation coefficient. Biometrics 15:469-485. https://doi.org/10.2307/ 2527750 .

Rogers, G. W., G. Banos, U. Sander Nielsen, and J. Philipsson. 1998. Genetic correlations among somatic cell scores, productive life, and type traits from the United States and udder health measures from Denmark and Sweden. J. Dairy Sci. 81:1445-1453. https:// doi.org/10.3168/jds.S0022-0302(98)75708-X.

Rogers, G. W., G. L. Hargrove, T. J. Lawlor Jr., and J. L. Ebersole. 1991. Correlations among linear type traits and somatic cell counts. J. Dairy Sci. 74:1087-1091. https://doi.org/10.3168/jds .S0022-0302(91)78259-3.

Rupp, R., and D. Boichard. 1999. Genetic parameters for clinical mastitis, somatic cell score, production, udder type traits, and milking ease in first lactation Holsteins. J. Dairy Sci. 82:2198-2204. https: //doi.org/10.3168/jds.S0022-0302(99)75465-2.

Shabalina, T., T. Yin, K. May, and S. Konig. 2021. Proofs for genotype by environment interactions considering pedigree and genomic data from organic and conventional cow reference populations. J. Dairy Sci. 104:4452-4466. https://doi.org/10.3168/jds.2020-19384.

Shook, G. E., and M. M. Schutz. 1994. Selection on somatic cell score to improve resistance to mastitis in the United States. J. Dairy Sci. 77:648-658. https://doi.org/10.3168/jds.S0022-0302(94)76995-2.

Sutherland, M. A., J. Webster, and I. Sutherland. 2013. Animal health and welfare issues facing organic production systems. Animals (Basel) 3:1021-1035. https://doi.org/10.3390/ani3041021.

Thomas, C. L., W. E. Vinson, R. E. Pearson, F. N. Dickinson, and L. P. Johnson. 1984. Relationships between linear type scores, objective type measures, and indicators of mastitis. J. Dairy Sci. 67:1281-1292. https://doi.org/10.3168/jds.S0022-0302(84)81435 $-6$.

USDA-AMS (USDA Agricultural Marketing Service). 2020. Organic Regulations. Accessed May 1, 2020. https://www.ams.usda.gov/ rules-regulations/organic.

USDA-NASS (USDA National Agricultural Statistics Service). 2017. Certified Organic Survey: 2016 Summary. Accessed Oct. 16, 2019. https://www.nass.usda.gov/Publications/Todays_Reports/ reports/census17.pdf.

van der Linde, C., G. De Jong, E. P. C. Koenen, and H. Eding. 2010. Claw health index for Dutch dairy cattle based on claw trimming and conformation data. J. Dairy Sci. 93:4883-4891. https://doi .org/10.3168/jds.2010-3183.

van der Waaij, E. H., M. Holzhauer, E. Ellen, C. Kamphuis, and G. De Jong. 2005. Genetic parameters for claw disorders in Dutch dairy cattle and correlations with conformation traits. J. Dairy Sci. 88:3672-3678. https://doi.org/10.3168/jds.S0022-0302(05)73053 $-8$.

VanRaden, P. M. 2004. Invited review: Selection on net merit to improve lifetime profit. J. Dairy Sci. 87:3125-3131. https://doi.org/ 10.3168/jds.S0022-0302(04)73447-5.

VanRaden, P. M. 2008. Efficient methods to compute genomic predictions. J. Dairy Sci. 91:4414-4423. https://doi.org/10.3168/jds .2007-0980.

VanRaden, P. M., J. B. Cole, and K. L. Parker Gaddis. 2018. Net Merit as a Measure of Lifetime Profit: 2018 Revision. Accessed May 18, 2020. https://aipl.arsusda.gov/reference/nmcalc-2018.htm.

VanRaden, P. M., and E. J. H. Klaaskate. 1993. Genetic evaluation of length of productive life including predicted longevity of live cows. J. Dairy Sci. 76:2758-2764. https://doi.org/10.3168/jds.S0022 -0302(93)77613-4.

VanRaden, P. M., J. R. Wright, M. E. Tooker, and H. D. Norman. 2016. Value of selecting for cow and calf livability. Pages 30-33 in Interbull Bulletin No. 50. Interbull

von Keyserlingk, M. A., and D. M. Weary. 2017. A 100-Year Review: Animal welfare in the Journal of Dairy Science-The first 100 years. J. Dairy Sci. 100:10432-10444. https://doi.org/10.3168/jds.2017 -13298 . 
von Keyserlingk, M. A. G., J. Rushen, A. M. de Passillé, and D. M. Weary. 2009. Invited review: The welfare of dairy cattle-key concepts and the role of science. J. Dairy Sci. 92:4101-4111. https:// doi.org/10.3168/jds.2009-2326.

Vukasinovic, N., N. Bacciu, C. Przybyla, P. Boddhireddy, and S. DeNise. 2017. Development of genetic and genomic evaluation for wellness traits in US Holstein cows. J. Dairy Sci. 100:428-438. https://doi.org/10.3168/jds.2016-11520.

Weigel, K. A., T. Kriegl, and A. L. Pohlman. 1999. Genetic analysis of dairy cattle production traits in a management intensive rotational grazing environment. J. Dairy Sci. 82:191-195. https://doi.org/10 .3168/jds.S0022-0302(99)75223-9.

Wiggans, G. R., P. M. VanRaden, and M. M. Schutz. 1994. Changes in USDA-DHIA genetic evaluations (January 1994). Publisher Animal Improvement Programs Laboratory, USDA-ARS.

Wiggans, G. R., P. M. VanRaden, D. J. Null, and J. B. Cole. 2019 Genomic predictions using more markers and gene tests. J. Dairy Sci. 102(Suppl. 1):397.

Zwald, N. R., K. A. Weigel, Y. M. Chang, R. D. Welper, and J. S. Clay. 2004a. Genetic selection for health traits using producer- recorded data. I. Incidence rates, heritability estimates, and sire breeding values. J. Dairy Sci. 87:4287-4294. https://doi.org/10 .3168/jds.S0022-0302(04)73573-0.

Zwald, N. R., K. A. Weigel, Y. M. Chang, R. D. Welper, and J. S. Clay. 2004b. Genetic selection for health traits using producer-recorded data. II. Genetic correlations, disease probabilities, and relationships with existing traits. J. Dairy Sci. 87:4295-4302. https: //doi.org/10.3168/jds.S0022-0302(04)73574-2.

\section{ORCIDS}

L. C. Hardie (ํ) https://orcid.org/0000-0001-9869-3447

I. W. Haagen (๑ https://orcid.org/0000-0003-1882-0798

B. J. Heins (®) https://orcid.org/0000-0003-2186-9082

C. D. Dechow (1) https://orcid.org/0000-0002-9012-2807 